\title{
Health Equity: The Only Path Forward for Primary Care
}

Tracey L. Henry, MD, MPH, MS

Jacqueline B. Britz, MD, MSPH ${ }^{2}$

Josbua St. Louis, MD, MPH, AAHIVS

Richard Bruno, MD, MPH, AAHIVS ${ }^{4}$

Carlos Irwin A. Oronce, MD, MPH,

Andrew Georgeson, MD

Braveen Ragunanthan, $M D, M P H^{8}$

Maya M. Green, MD, MS

Neeti Doshi, MD, MPH ${ }^{10}$

Alison N. Huffstetler, $M D^{2}$

'Emory University School of Medicine, Division of General Medicine and Geriatrics, Atlanta, Georgia

${ }^{2}$ Virginia Commonwealth University, Department of Family Medicine and Population Health, Richmond, Virginia

${ }^{3}$ Department of Family Medicine, Tufts University School of Medicine, Boston, Massachusetts; Lawrence Family Medicine Residency, Lawrence, Massachusetts

${ }^{4}$ Chase Brexton Health Care, Baltimore, Maryland

${ }^{5}$ Veterans Affairs Advanced Health Services Research Fellowship, Greater Los Angeles VA Healthcare System, Los Angeles, California

${ }^{6}$ David Geffen School of Medicine, University of California Los Angeles, Los Angeles, California

${ }^{7}$ Kids Plus Pediatrics, Pittsburgh, Pennsylvania

${ }^{8}$ Delta Health Center, Inc, Mound Bayou, Mississippi

${ }^{9}$ Locum Tenens, Gaithersburg, Maryland

${ }^{10}$ University of California San Francisco Department of Pediatrics, San Francisco, California

Conflicts of interest: authors report none.

\section{CORRESPONDING AUTHOR}

Alison N. Huffstetler

Virginia Commonwealth University

Suite 600, 830 East Main Street

Richmond, Virginia, 23298

alison.huffstetler@vcuhealth.org

\begin{abstract}
The 2021 National Academies of Sciences, Engineering, and Medicine (NASEM) report on Implementation of High-Quality Primary Care identifies 5 high-level objectives regarding payment, access, workforce development, information technology, and implementation. Nine junior primary care leaders ( 3 internal medicine, 3 family medicine, 3 pediatrics) invited from broad geographies, practice settings, and academic backgrounds used appreciative inquiry to identify priorities for the future of primary care. Highlighting the voices of these early career clinicians, we propose a response to the report from the perspective of early career primary care physicians. Health equity must be the foundation of the future of primary care. Because Barbara Starfield's original 4 Cs (first contact, coordination, comprehensiveness, and continuity) may not be inclusive of the needs of under-resourced communities, we promote an extension to include 5 additional Cs: convenience, cultural humility, structural competency, community engagement, and collaboration. We support the NASEM report's priorities and its focus on achieving health equity. We recommend investing in local communities and preparatory programs to stimulate diverse individuals to serve in health care. Finally, we support a blended value-based care model with risk adjustment for the social complexity of our patients.
\end{abstract}

Ann Fam Med 2022;20:Online. https://doi.org/10.1370/afm.2789.

Annals "Online First" article. Accepted for publication in a later issue.

\section{INTRODUCTION}

fter the release of the 2021 National Academies of Sciences, Engineering,
and Medicine (NASEM) report on Implementation of High-Quality Primary Care,
a group of early career primary care clinicians gathered to reflect on the report and its implications for the future of primary care. ${ }^{1}$ The 9 participants ( 3 family medicine $[\mathrm{FM}], 3$ internal medicine [IM], 3 pediatrics [peds]) and 2 facilitators from across the United States represent varied settings, including academic, community, federally qualified health center, and locums. The group convened monthly beginning in November 2020 to discuss innovative strategies in delivering high-quality, equitable, and cost-effective primary care.

NASEM sees primary care as the cornerstone of a functional and equitable health care system and articulates 5 high-level objectives: payment, access, workforce development, information technology, and implementation with strategies to support survival and sustainability of primary care. ${ }^{1}$ Changes in primary care today will affect clinicians in the field for decades. Although many organizational leadership opportunities exist, the voice of early career clinicians is often overlooked. Though some cross-specialty collaborations exist, there are few. ${ }^{2}$ We present a unified response from early career multi-specialty physicians on the strategic implementation and potential impact of the NASEM recommendations on the future of health care delivery.

Senior academic leaders identified clinicians in internal medicine, family medicine, and pediatrics who were within 10 years of their terminal degree, with attention to broad demographics, geographies, practice settings, and academic backgrounds. Six facilitated monthly discussions, lasting 2 hours each, explored primary care priorities from the perspective of the early career clinicians. Facilitation was conducted utilizing appreciative inquiry, which prompts participants to consider the following: define, discover, dream, design, and deliver. ${ }^{4}$ The facilitator notes were analyzed after each meeting to identify emerging themes, and a final analysis identified health equity as the driver of primary care. Key elements of discussion from each session are shown in Supplemental Table 1.

Three themes emerged as common threads through each session: envisioning the 4 C's of primary care (first contact accessibility, coordination, 
comprehensiveness, and continuity) through equity, equitable representation in team-based care, and equitable financing for primary care (Table 1). Equity is the final priority, the only path forward, and is key to all decision making and policy recommendations, especially as it relates to implementing high-quality primary care in the United States.

\section{THE STARFIELD 4 Cs OF PRIMARY CARE AND 5 ADDITIONAL Cs}

High-functioning primary care systems have better health outcomes, lower health care costs, increase patient satisfaction and improve health equity compared with poorly functioning systems. ${ }^{5}$ As we attempt to focus more on health equity, are the $4 \mathrm{Cs}$ advanced by Dr Barbara Starfield still relevant? Her 4 essential features of primary care were first contact, continuity, coordination, and comprehensiveness and she illustrated their association with health equity, costcontainment, patient-centered care, and improved population health. ${ }^{6}$ Other scholars such as Kroenke added 6 more Cs: competence, cost-effectiveness, communication, collaboration, compliance, and competing demands. The NASEM report reiterated these concepts. ${ }^{7,8}$ Specifically, the report states "high-quality primary care is the provision of wholeperson, integrated, accessible, and equitable health care by interprofessional teams that are accountable for addressing the majority of an individual's health and wellness needs across settings and through sustained relationships with patients, families, and communities."

However, inequities in the US health care system and systemic racism pose barriers to realizing these goals and must be intentionally addressed. Under-resourced communities and patients are unable to benefit from the $4 \mathrm{Cs}$ due to foundationally flawed systems. Fragmentation of care, lack of access to primary care, and clinical inability to maintain continuity have reduced health equity. ${ }^{9,10}$ Additionally, certain delivery models have emphasized 1 of the 4 Cs more than the others which exacerbates health inequities; namely, the patient-centered medical home overemphasizes care

\section{Table 1. Early Career Physicians Adapted and Endorsed 2021 NASEM Report} on Implementing High-Quality Primary Care Recommendations

\begin{tabular}{|c|c|}
\hline Theme & Recommendation \\
\hline $\begin{array}{c}\text { The } 4 \text { Starfield Cs of primary } \\
\text { care and } 5 \text { additional Cs }\end{array}$ & $\begin{array}{l}\text { 1. Structure health care systems to prioritize the extended } 4 \text { Cs } \\
\text { of primary care to include additionally: convenience, cultural } \\
\text { humility, structural competency, community engagement, and } \\
\text { collaboration. }\end{array}$ \\
\hline The primary care workforce & $\begin{array}{l}\text { 2. Advance diversity in medicine through purposeful recruit- } \\
\text { ment, hiring, education, and training of health care teams that } \\
\text { reflect the demographics of the population served. }\end{array}$ \\
\hline $\begin{array}{l}\text { Primary care payment and } \\
\text { incentives }\end{array}$ & $\begin{array}{l}\text { 3. Establish alternative, risk-adjusted payment models for pri- } \\
\text { mary care to reward coordinated and comprehensive care for } \\
\text { all patients and among all payers. }\end{array}$ \\
\hline
\end{tabular}

coordination in an attempt to compensate for lack of comprehensiveness and continuity. ${ }^{11}$

For the Starfield 4 Cs to be actualized, we would add 5 additional Cs: convenience, cultural humility, structural competency, community engagement, and collaboration. Primary care must meet needs based on communities' and individuals' own needs, traits, and values. For example, primary care mobile units and street medicine allow homebound individuals and those experiencing homelessness to continue to receive care. Brick and mortar primary care clinics should be located geographically where their patients live and in all communities. Technologies such as telehealth, remote patient monitoring, and expanded office hours will improve convenience. When providing person-centered care, the values and priorities of communities should be considered to attain cultural humility. As medical systems increase subspecialization, primary care must emphasize comprehensiveness by allowing clinicians to maintain competence in care across a wide range of diseases, settings, and procedures. ${ }^{12,13}$ The final new $\mathrm{C}$ is collaboration, which must take place between clinicians, allied health care workers, patients, and communities to promote people-centered care.

\section{THE PRIMARY CARE WORKFORCE}

To achieve collaboration and health equity, we must develop a diverse and inclusive health care workforce. Health professions must prioritize educating and recruiting physicians, nurses, dentists, pharmacists, and other allied health professionals from diverse racial/ethnic, socioeconomic backgrounds, especially those underrepresented in medicine (URiM): Black, Hispanic and Latinx/o/a, and Native Americans.

Despite efforts, the supply of URiM physicians does not adequately match the population, and the distribution between rural and urban is unequal. The US physician workforce is only made up of $5 \%$ Black or African American doctors with no major significant percentage increase in roughly 50 years. ${ }^{14}$ According to the 2015 Association of American Medical Colleges' Altering the Course report, Black males were $3.1 \%$ of the physician workforce, but, shockingly, in 2019, they were $2.9 \%$, essentially unchanged despite the "advances" in racial equity and justice. ${ }^{15,16}$ Some medical schools are training students in rural communities with the hopes they will remain where they train. ${ }^{17}$ To recruit and train students adequately for successful careers as physicians and in other health professions, schools must partner and invest in preparatory programs to engage students and garner an interest in higher education. The clinician workforce, alongside all 
primary care team members, should partner with the communities they serve. Team-based care models should be supported because they are better equipped to address health and social inequities compared to siloed and individual clinicians. Wellfunctioning teams have improved outcomes at reduced costs to the health care system. ${ }^{18}$ Team-based care should extend beyond the walls of the clinic. When residents of Philadelphia were asked, "What do you need to improve your health?" many answered with needs that are not usually met within the bounds of an exam room. Respondents needed mental health and behavior change support, resources for daily living, and health care navigation. ${ }^{19}$ Teams able to effectively address these priorities are key to equitable health care delivery.

\section{PRIMARY CARE PAYMENT AND INCENTIVES}

We witness burnout in our early career colleagues and watch peers leave primary care. Medical students talk about their hesitancy to enter primary care due to high patient volume, insurance regulations, and limited remuneration. The financial ramifications of disparate primary care payments have resulted in extreme burnout. Especially in primary care, ${ }^{20}$ our under-resourced primary care systems struggle to meet patients' needs. Payment reform is required to make sustainable changes that will reduce burnout, improve quality care, and drive workforce development. The NASEM report provides a roadmap to payment reform; we endorse 2 recommendations that have significant implications for health equity.

First, as the NASEM report argues, replacing fee-for-service (FFS) payments with hybrid models that blend existing FFS with capitated payments should be a key priority. The current fee-for-service environment incentivizes volume without regard to quality or the other features of the $4 \mathrm{Cs}$ that make the adoption of high-quality primary care financially difficult. A fully capitated model with risk-adjusted payments would allow practices to focus on building processes that facilitate the necessary practice transformation to achieve equitable contact, coordination, comprehensiveness, and continuity while striving for cultural humility, convenience, and collaboration.

A sudden shift to a global capitated payment model in which physicians take on all risk would be too disruptive to facilitate the necessary practice changes. Rather, models that blend a capitated payment with FFS for the care of primary care patient populations already exist and can be used as a template. The Centers for Medicare and Medicaid Services Innovation Center's Comprehensive Primary Care (CPC) Initiative and its successor, CPC+, offer combined risk-adjusted payments for each patient within the FFS system. The multiplayer demonstration project was associated with a reduction in hospitalization and emergency department visit rates over the long term. ${ }^{21}$ Critical to the success of such models is appropriate risk adjustment in quality measurement and payment that accounts for social complexity. Thus, we are not penalized for caring for under-resourced patient populations that require specific interventions to address disparities and unmet health-related social needs. ${ }^{22}$ Such financing of primary care would help fulfill the NASEM report's first stated objective: "Pay for primary care teams to care for people, not doctors to deliver services." 1

Second, a multi-payer collaboration on payment models and fee schedules is necessary and should be matched by state Medicaid agencies. Medicaid reimbursement for primary care is inadequate and contributes to difficulties in equitable access to care. Given that Medicaid disproportionately serves minoritized and under-resourced communities, inadequate reimbursement in primary care reinforces the segregation of health services in the United States. Specifically, we bear witness to disparities not only in access to care in nonexpansion states, but even more egregious is the situation where the patients, once in care, in safety-net systems, are still unable to afford necessary medications, treatments, and specialty care. COVID-19 revealed how this health care segregation contributed to the stark racial disparities in mortality. States should deliberately increase Medicaid reimbursements to reach parity with commercial payers to encourage an equitable safety net. Primary care spending in each state should be increased to $5 \%$, at minimum, similar to other high-income countries that have better health outcomes without the United States' steep total health care spend. This additional payment would fund adequate facilities, population health resources, workforce, and the factors that facilitate access and the $9 \mathrm{C}^{\prime}$ s.

For decades, numerous reports' and leaders' calls for a focused effort on restructuring and refinancing primary care have gone largely unanswered. In actualizing any of these proposed initiatives for primary care, equity must be at the forefront. Health equity as an afterthought is a threat to the sustainability of any high-functioning primary care system. As a result, we endorse 3 recommendations adapted from the 2021 NASEM $^{\text {report }}{ }^{1}$ that are critical to promoting health equity (Table 1).

To make these changes, we need a concerted effort across the health care system, across all primary care specialties and members of the health care team, including advanced practice providers, social workers, nursing, and behavioral health among others to help advance these directives.

Further, we encourage our early career physician colleagues to become involved in leadership at the local and national levels to advocate for the patient and communities they serve. Ultimately, equity in primary care can only be rightfully achieved when we have a more equitable, just society in all systems: social, economic, educational, and criminal justice. If we early career physicians want to see change in the decades to come, we have to be involved where we are. We have the expertise and our voice matters. We can no longer wait for those before us to change the future of medicine.

Read or post commentaries in response to this article.

Key words: primary health care; social justice; health equity; risk adjustment; workforce 
Submitted August 19, 2021; submitted, revised, December 1, 2021; accepted December 6, 2021.

Funding support: This project was funded by the Larry A. Green Center for the Advancement of Primary Health Care for the Public Good and Virginia Commonwealth University School of Medicine. Dr Oronce was supported by the VA Office of Academic Affiliations through the VA Advanced HSR Fellowship.

Disclaimer: The contents do not represent the views of the U.S. Department of Veterans Affairs or the United States Government.

Acknowledgments: The authors thank Rebecca S. Etz, PhD; Alex Krist, MD, MPH; Robert L. Phillips, MD, MSPH; Laura Sessums, MD, JD; Jennifer DeVoe, MD; Kurt Stange, MD, PhD; Larry A. Green, MD; Stephanie A. Gold, MD; Alexandra Ristow, MD and Steven H. Woolf, MD, MPH.

\section{Supplemental materials}

\section{References}

1. National Academies of Sciences, Engineering, and Medicine. Implementing High-Quality Primary Care: Rebuilding the Foundation of Health Care. The National Academies Press; 2021. 10.17226/25983

2. America's frontline physicians: the group of six. Accessed Aug 1, 2021. https://groupofsix.org

3. Green J, Browne J. Principles of Social Research. Open University Press; 2005.

4. Cooperrider DL, Whitney D. Appreciative Inquiry: A Positive Revolution in Change. Berrett-Koehler Publishers; 2005.

5. Schäfer WLA, Boerma WGW, van den Berg MJ, et al. Are people's health care needs better met when primary care is strong? A synthesis of the results of the QUALICOPC study in 34 countries. Prim Health Care Res Dev. 2019;20:e104. $10.1017 /$ S1463423619000434

6. Starfield B. Primary Care: Balancing Health Needs, Services, and Technology. Oxford University Press; 1998.

7. Phillips RL Jr, McCauley LA, Koller CF. Implementing high-quality primary care: a report from the National Academies of Sciences, Engineering, and Medicine. JAMA. 2021;325(24):2437-2438.

8. Kroenke K. The many C's of primary care. J Gen Intern Med. 2004;19(6):708709. 10.1111/j.1525-1497.2004.40401.x

9. Lloyd HM, Pearson M, Sheaff R, et al. Collaborative action for personcentred coordinated care ( $\mathrm{PCC}$ ): an approach to support the development of a comprehensive system-wide solution to fragmented care. Health Res Policy Syst. 2017;15(1):98. 10.1186/s12961-017-0263-z
10. Doose M, Sanchez JI, Cantor JC, et al. Fragmentation of care among black women with breast cancer and comorbidities: the role of health systems. JCO Oncol Pract. 2021;17(5):e637-644. 10.1200/OP.20.01089

11. Berenson RA, Burton R. How solid is the primary care foundation of the medical home? Health Affairs blog. Mar 25, 2016. https://www.health affairs.org/do/10.1377/hblog20160325.054144/full/

12. Institute of Medicine. Crossing the Quality Chasm: A New Health System for the 21st Century. National Academy Press; 2001.

13. Shi L. The impact of primary care: a focused review. Scientifica. Volume 2012:1-22. 10.6064/2012/432892

14. Ly DP. Historical trends in the representativeness and incomes of black physicians, 1900-2018 [published online ahead of print Apr 19, 2021]. J Gen Intern Med. https://link.springer.com/content/pdf/10.1007/s11606-02106745-1.pdf

15. Brownlee D. Why are black male doctors still so scarce in America? Forbes. Published Aug 11, 2020. Accessed Oct 2, 2021. https://www.forbes.com/ sites/danabrownlee/2020/08/11/why-are-black-male-doctors-still-so-scarce-inamerica/?sh $=26277 \mathrm{e} 5627 \mathrm{c} 2$

16. Morris DB, Gruppuso PA, McGee HA, Murillo AL, Grover A, Adashi EY. Diversity of the national medical student body - four decades of inequities. N Engl J Med. 2021;384(17):1661-1668. 10.1056/NEJMsr2028487

17. Cathcart-Rake W, Robinson M, Owings $S$, et al. The birth of a rural medical school-the University of Kansas School of Medicine-Salina experience. Med Sci Educ. 2012;22:250-258. 10.1007/BF03341793

18. Reiss-Brennan B, Brunisholz KD, Dredge $C$, et al. Association of integrated team-based care with health care quality, utilization, and cost. JAMA. 2016; 316(8):826-834. 10.1001/jama.2016.11232

19. National Academies of Sciences, Engineering and Medicine. Investing in Interventions That Address Non-Medical, Health-Related Social Needs: Proceedings of a Workshop. The National Academies Press; 2019.

20. Primary Care Collborative. Eighty percent of primary care clinicians say professional burnout is at an all-time high. Primary Care Collaborative. Published Jun 18, 2020. Accessed Aug 18, 2021. https://www.pcpcc.org/2020/ 06/18/80-percent-primary-care-clinicians-say-their-level-burnout-all-time-high

21. Fu N, Singh $P$, Dale $S$, et al. Long-Term effects of the comprehensive primary care model on health care spending and utilization. J Gen Intern Med. 2021; 10.1007/s11606-021-06952-w

22. Nerenz DR, Austin JM, Deutscher D, et al. Adjusting quality measures for social risk factors can promote equity in health care. Health Aff (Millwood). 2021;40(4):637-644. 